\title{
Flexural Behavior of Ultra-High Performance Fiber Reinforced Concrete Scale Tunnel Segment
}

\author{
Kun NI, Fa Sheng ZHANG, Yun Xing SHI, Yan Gang ZHANG, Jing Bin SHI \\ Technical Center, China State Construction Engineering Corporation, Beijing, China
}

\begin{abstract}
To reduce the weight of precast tunnel segment, ultra-high performance fiber reinforced concrete (UHPFRC) was studied to cast the segment. The flexural performance of UHPFRC scale tunnel segments were tested in this work. The weight of the UHPFRC thinner scale tunnel segment was only $80 \%$ of reinforced concrete (RC) segment. The segments were loaded as per CJJ/T 164-2011, and the four-point bending system was used. The results showed that the cracking load increased $50 \%$, and $0.2 \mathrm{~mm}$ crack width load increased $22 \%$, and the yield load increased $11 \%$, and the ultimate load only decreased $1 \%$. The stiffness of elastic stage of UHPFRC segment looked the same compared to RC segment. In a word, the UHPFRC thinner segments showed excellent flexural performance beyond the traditional RC segment.
\end{abstract}

\section{Introduction}

Shield tunneling method is rapidly growing in metro construction of Chinese city. Precast tunnel segment is structure unit, which was assembled through tunnel boring machine (TBM) to build the tunnel. It can be manufactured with reinforced concrete, steel, iron or composite materials. Reinforced concrete (RC) is widely used due to its good durability and low-cost among these materials. And precast concrete tunnel segment has higher manufacturing quality and building effectiveness compared to cast in situ concrete. However, RC segment is heavy; the steel rebar reinforcing cage of $\mathrm{RC}$ segment is complicated; the concrete is susceptible to spalling in fire. And during the installation process of segments and tunneling process of TBM, accidental thrust and impact loads are dominant and may result in segment cracking.

The fiber reinforced concrete (FRC) segment has excellent toughness, crack arrestment, durability and fire resistance. And the process of steel rebar reinforcing cage is more efficient, because the steel fibers could partially or totally substitute traditional reinforcement [1-3]. However, the FRC segment is still heavy.

Ultra-high performance fiber reinforced concrete
(UHPFRC) performs a high mechanical strength $[4,5]$ and durability[6], improved resistance against various chemicals as well as higher penetration resistance[7]. To decrease the weight of concrete segment, UHPFRC was used to manufacture the segment and the flexural performance of the segment was tested and discussed in this study.

\section{Experiment}

\subsection{Raw materials.}

The constituent materials used to produce concrete comprised of 42.5R and 52.5R Portland cement, fly ash, manufactured sand, 5-20 mm gravel, polycarboxylate SP (solid content $\approx 40 \%$ ), silicone defoaming agent, polypropylene fiber and hooked end steel fiber. The polypropylene fiber length and diameter are $18 \mathrm{~mm}$ and $26 \mu \mathrm{m}$, and the steel fibers length and diameter are 60 $\mathrm{mm}$ and $0.9 \mathrm{~mm}$, respectively. The main rebar is HRB400, and its diameter is $16 \mathrm{~mm}$, and the yield tensile strength and ultimate tensile strength is $470 \mathrm{MPa}$ and 640 $\mathrm{MPa}$. All the materials are produced in China.

Table 1 The mix proportions of concrete

Unit: $\mathrm{kg} / \mathrm{m}^{3}$

\begin{tabular}{cccccccccccc}
\hline & $\begin{array}{c}\text { Cement } \\
42.5 \mathrm{R}\end{array}$ & $\begin{array}{c}\text { Cement } \\
52.5 \mathrm{R}\end{array}$ & $\begin{array}{c}\text { Fly } \\
\text { ash }\end{array}$ & $\begin{array}{c}\text { Silica } \\
\text { fume }\end{array}$ & Sand & Gravel & Water & SP & $\begin{array}{c}\text { Steel } \\
\text { fiber }\end{array}$ & $\begin{array}{c}\text { PP } \\
\text { fiber }\end{array}$ & $\begin{array}{c}\text { defoaming } \\
\text { agent }\end{array}$ \\
\hline HSC & 440 & - & 110 & - & 800 & 940 & 187 & 2.2 & - & 1 & - \\
UHPFRC & & 440 & 110 & 38.5 & 800 & 940 & 147 & 6.8 & 55 & 1 & 0.55 \\
\hline
\end{tabular}

\footnotetext{
* Corresponding author: nikunun@126.com
} 


\subsection{Concrete.}

The mix proportions are shown in Table 1 that was used for UHPFRC and high strength concrete (HSC) as match. The HSC was used to produce the traditional RC segment, and the UHPFRC was used to make the thinner UHPFRC segment.

The strengths of concrete are shown in Table 2. The strength of both concrete were reached $60 \mathrm{MPa}$ and
$100 \mathrm{MPa}$. The flexural performance of the concrete was obtained according to the standard RILEM TC 162-TDF recommendation. The parameters are limit of proportionality $\left(f_{\mathrm{L}}\right)$, ultimate flexural strength $\left(f_{\mathrm{u}}\right)$, and equivalent tensile strength $\left(f_{\text {eq, } 2}, f_{\text {eq, } 3}\right)$. It was shown that the $f_{\mathrm{L}}$ increased $50 \%$, and the $f_{\mathrm{u}}$ increased $200 \%$, and the post cracking strengths $\left(f_{\text {eq }, 2}, f_{\text {eq }, 3}\right)$ were more than double $f_{\mathrm{u}}$ of HSC.

Table 2 The strength of concrete

Unit: $\mathrm{kg} / \mathrm{m}^{3}$

\begin{tabular}{cccccc}
\hline & $\begin{array}{c}\text { Compressive } \\
\text { strength }\end{array}$ & $f_{\mathrm{L}}$ & $f_{\mathrm{u}}$ & $f_{\mathrm{eq} 2}$ & $f_{\mathrm{eq} 3}$ \\
\hline HSC & 68.3 & 3.87 & 4.04 & & \\
UHPFRC & 106 & 5.95 & 11.92 & 9.33 & 10.67 \\
\hline
\end{tabular}

\subsection{Precast segment description.}

The segment ring is composed of eight segments. The tested segment geometry is shown in Figure1. The thickness of comparison RC segment was $270 \mathrm{~mm}$. The thickness of UHPFRC segment was $225 \mathrm{~mm}$. The thickness reduced by $16.7 \%$. The rebar cages are shown in Figure2. Longitudinal rebar is $16 \mathrm{~mm}$, and the other rebar is $12 \mathrm{~mm}$. The longitudinal reinforcement in UHPFRC segment is $80 \%$ of that in RC segment and the hooping is $50 \%$.
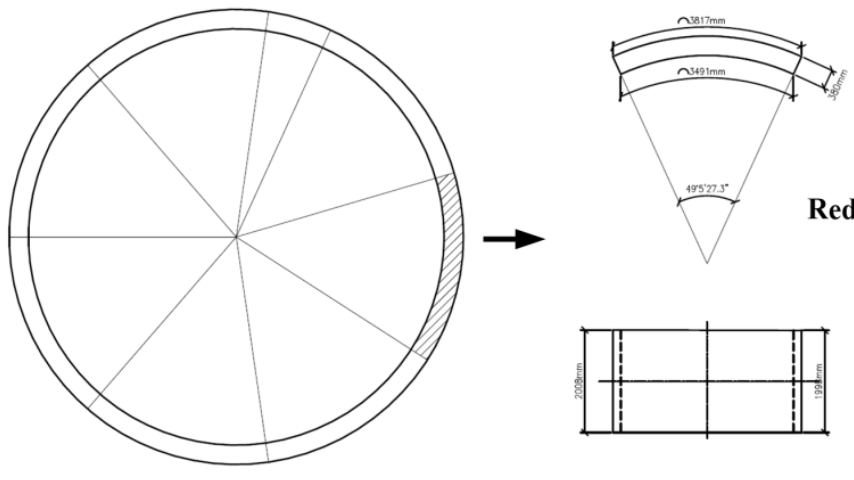

Figure 1 Tunnel segment geometry
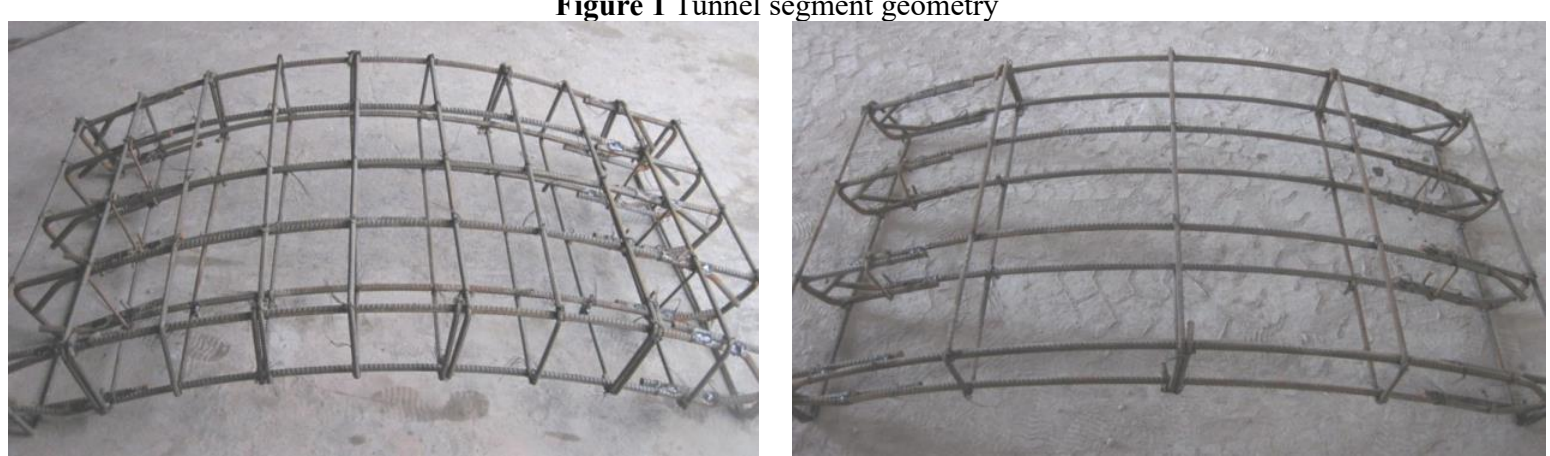

Figure 2 The rebar cage of segments (Left: RC segment; Right: UHPFRC segment)

\subsection{Flexural of segment test.}

The segments were loaded as per CJJ/T 164-2011. The loading system was four-point bending. It is shown in Figure3. The distance between two loading line was $635 \mathrm{~mm}$. The testing segment was support on sliding block. The reaction frame having a maximum bearing capacity was $2000 \mathrm{kN}$. Each type of segment has two specimens. The segment was under multi-stage loading. When the loading kept the stage, the crack openings were observed and measured using the electronic crack width tester. After the width of crack was beyond $0.2 \mathrm{~mm}$, continuous loading was running until the load dropped suddenly. In whole process, the deformations were tested by linear variable displacement transducers (LVDTs). 


\section{Results and discussion}

\subsection{Load-deformation relationships of segment.}

The load-middle deformation curves of two types

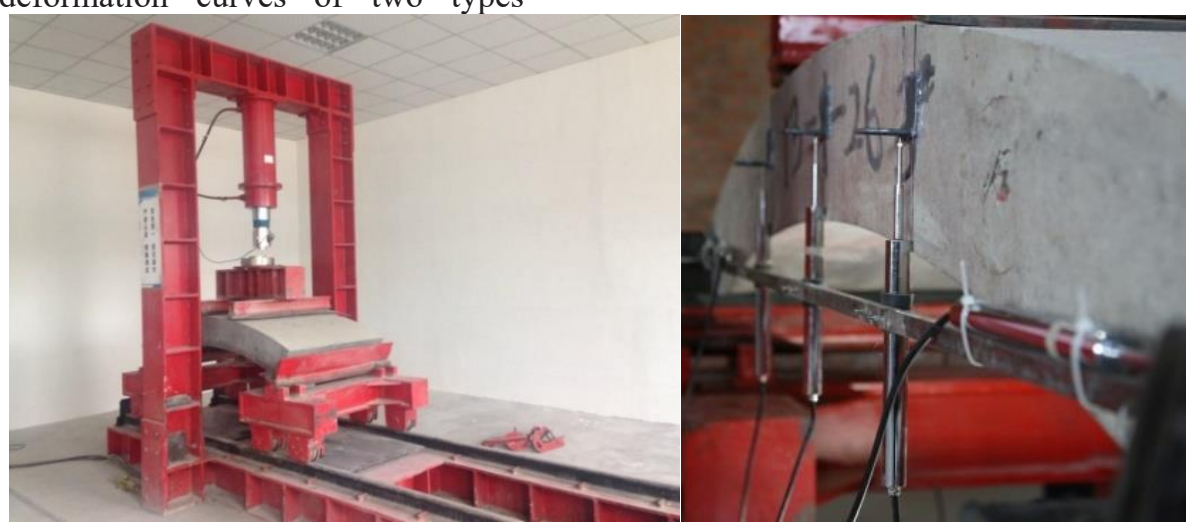

Figure 3 The segment flexural testing setup

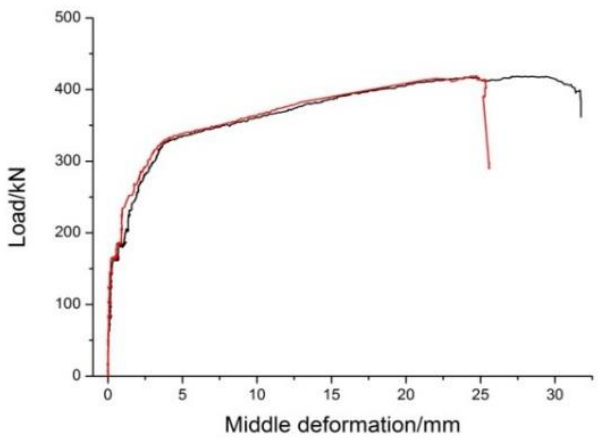

Figure 4 The load-middle deformation curves (Left: RC segment; Right: UHPFRC segment)

\subsection{Load-cracking response.}

The load-maximum crack width curves of $\mathrm{RC}$ and UHPFRC segments are shown in Figure 8. For UHPFRC segment, the first crack was observed at $120 \mathrm{kN}$. And for $\mathrm{RC}$ segment, the first crack was at $80 \mathrm{kN}$. For each load stage the crack of UHPFRC segments were narrower than that of RC segments. UHPFRC segments was excellent at the limiting the development of cracks.

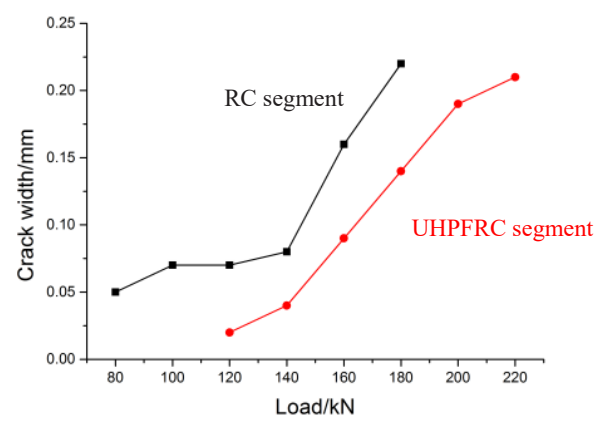

Figure 5 The load-crack width curves of RC and UHPFRC segments

segments are shown in Figure 4. The curves of the RC segment showed obvious yield point, and the yield came suddenly. But the yield process of UHPFRC segment was mildly because of the work of steel fiber.

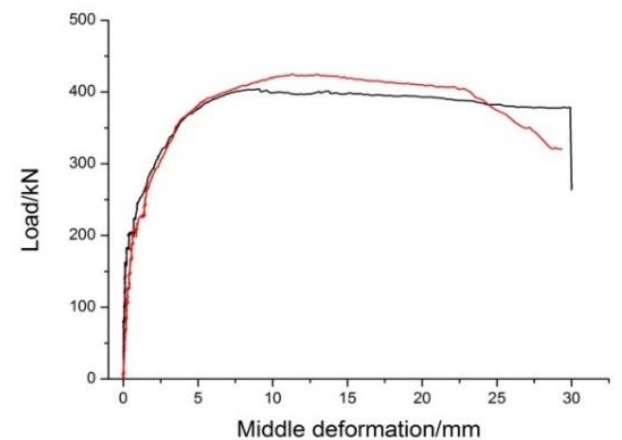

The crack pattern and failure morphology are shown in Figure6. The photograph indicated that all tested scale tunnel segments exhibited a flexural failure mechanism. But there were some differences between two types segments. On the bottom of segments, there were many vertical cracks on the RC segment, but there were only one wide crack on the UHPFRC segment. On the side of segments, the cracks showed that the load of RC segment dropped because the concrete was broken in the top of segment, and the reason was too wide crack for the load drop of the UHPFRC segment. 

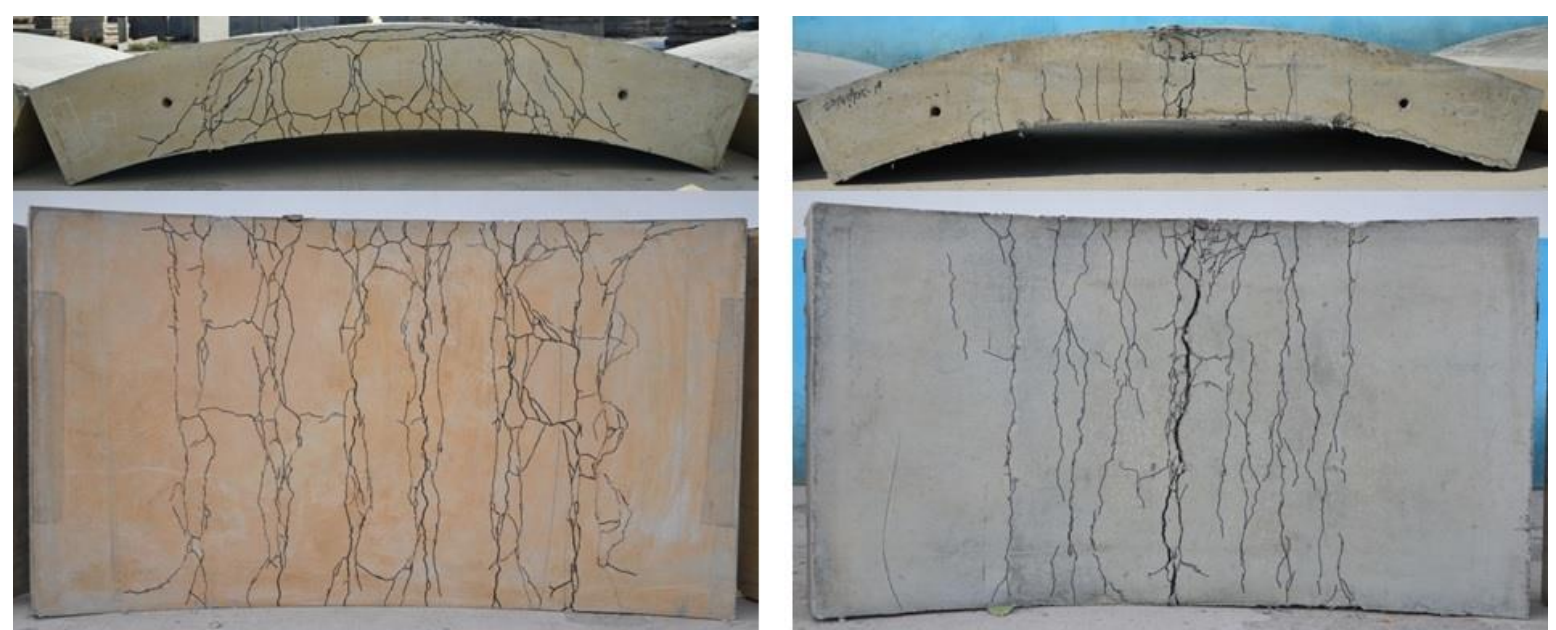

Figure 6 The crack pattern and failure morphology (Left: RC segment; Right: UHPFRC segment)

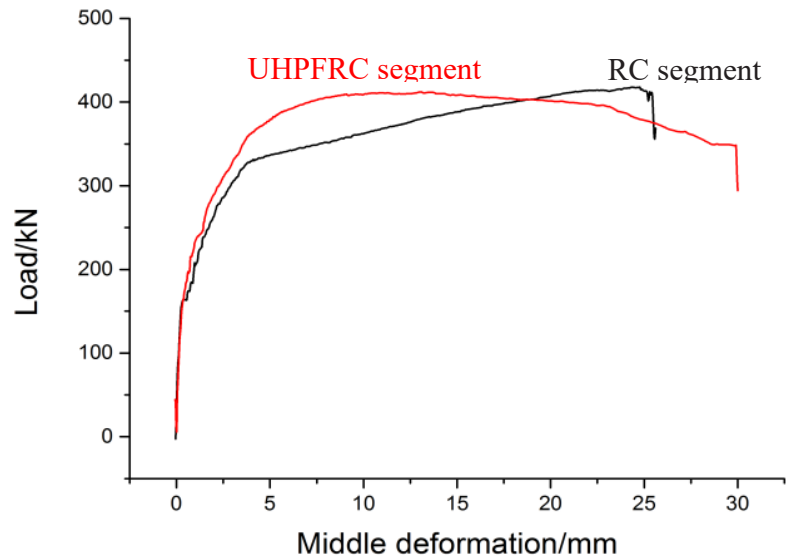

Figure 7 The compare of load-middle deformation curves of two types segments

\subsection{Flexural performance of segment.}

The segment is used under the ground. The environment of tunnel is complex and unpredictable. The design of segment is careful. The accepted crack width limit for serviceability conditions is $0.2 \mathrm{~mm}$ according to Chinese standard GB50010.

Therefore, it was defined that the $0.2 \mathrm{~mm}$ crack width load was the load leading to the first $0.2 \mathrm{~mm}$ crack. The yield loads and ultimate loads obtained from these load-middle deformation curves in Figure4. The cracking loads, $0.2 \mathrm{~mm}$ crack loads, yield loads and ultimate loads are listed in Table 3. The cracking load of UHPFRC segment increased $22 \%$, and the yield load increased $11 \%$, and the ultimate load only decreased $1 \%$. The flexural strength of UHPFRC segment is higher than RC segment.

Table 3 The flexural performance of segment

Unit:kN

\begin{tabular}{ccccc}
\hline & Cracking load & $\begin{array}{c}0.2 \text { mm crack } \\
\text { width load }\end{array}$ & Yield load & Ultimate load \\
\hline RC segment & 80 & 180 & $324-327$ & $418-419$ \\
UHPFRC segment & 120 & 220 & $360-363$ & $404-425$ \\
\hline
\end{tabular}

To the thinner segment, the stiffness is very important. The calculation of stiffness is complicated. But it can be compared simply using the slope of the load-middle deformation curves. The curves of two types of segments were showed together in Figure 7. The slopes of two curves looked the same in the elastic stage, and the slope of UHPFRC segment was a little smaller in the elastic-plastic stage. It means that the UHPFRC segment

has a similar stiffness to RC segment.

\section{Conclusion}

The flexural behavior of UHPFRC thinner scale tunnel segment was studied in this work. Form the result of experiments, the following conclusion was draw.

Compared to the traditional $\mathrm{RC}$ segment, the 
longitudinal reinforcement ratio, the hooping, and the thickness and of the UHPFRC scale segment got a $20 \%$, $50 \%$ and $17 \%$ reduction. The weight was the $80 \%$ of RC segment. However, the cracking load increased $50 \%$, and $0.2 \mathrm{~mm}$ crack width load increased $22 \%$, and the yield load increased $11 \%$, and the ultimate load only decreased $1 \%$. The flexural strength of UHPFRC segment was higher than RC segment. And the load-middle deformation curves showed the stiffness of UHPFRC segment was similar to that of $\mathrm{RC}$ segments. The flexural performance of UHPFRC segment was more excellent than that of RC segment.

\section{Acknowledgements}

This work was financially supported by China State Construction Engineering Corporation TCYT-2012A-007 and CSCEC-2016-Z-20-10.

\section{References}

1. Abbas, S., Soliman, A.M., Nehdi, M.L., Experimental study on settlement and punching behavior of full-scale RC and SFRC precast tunnel lining segments[J]. Engineering Structures, 2014, 72: $1-10$.

2. Caratelli, A., Meda, A., Rinaldi, Z., Romualdi, P., Structural behaviour of precast tunnel segments in fiber reinforced concrete[J]. Tunnelling and Underground Space Technology, 2011, 26: 284-291.

3. De la Fuente, A., Pujadas, P., Blanco, A., Aguado, A., Experiences in Barcelona with the use of fibres in segmental linings[J]. Tunnelling and Underground Space Technology, 2012, 27: 60-71.

4. P. Máca, R. Sovják, T. Vavřiník, Experimental Investigation of Mechanical Properties of UHPFRC, Procedia Engineering, 2013, 65: 14-19.

5. K. Wille, S. El-Tawil, A.E. Naaman, Properties of strain hardening ultra high performance fiber reinforced concrete (UHP-FRC) under direct tensile loading, Cement and Concrete Composites, 2014, 48: 53-66.

6. W. Wang, J. Liu, F. Agostini, C.A. Davy, F. Skoczylas, D. Corvez, Durability of an Ultra High Performance Fiber Reinforced Concrete (UHPFRC) under progressive aging, Cement and Concrete Research, 2014, 55: 1-13.

7. M. Alkaysi, S. El-Tawil, Z. Liu, W. Hansen, Effects of silica powder and cement type on durability of ultra high performance concrete (UHPC), Cement and Concrete Composites, 2016, 66: 47-56. 